\title{
Um agente na construção do habitus das ciências sociais na saúde coletiva*
}

\begin{abstract}
A lembrança da vida da gente se guarda em trechos diversos, cada um com seu signo e sentimento, uns com os outros acho que nem não se misturam. Contar seguido, alinhavado, só mesmo sendo as coisas de rasa importância. Assim eu acho, assim eu conto. Tem horas antigas que ficaram mais perto da gente do que outras, de recente data. (Rosa, 1984, p.92)
\end{abstract}

Quase quarenta anos separam o meu ingresso como professor na Faculdade de Ciências Médicas da Universidade Estadual de Campinas e a primeira aula que ministrei a estudantes de medicina, do dia de hoje. O tema da aula foi "Cultura: conceito e características: mudança cultural e barreiras na mudança"; local, o auditório Paulistão, no prédio da Santa Casa de Misericórdia, para onde havia se transferido a Faculdade Ciências Médicas; data: 5 de maio de 1967. Cito-a, pois foi a minha primeira aula expositiva ministrada aos alunos da $4 a$. Turma de Estudantes de Medicina, a 21a. aula teórica do Curso de Ciências Sociais aplicadas à Medicina. Tendo ingressado na Faculdade em março do mesmo ano, já havia participado das diversas atividades desse curso, como discussões em grupos e visitas domiciliares junto ao programa de clínica de família, num bairro da periferia de Campinas.

Mas, não se preocupem. Não farei um relato autobiográfico num sentido estrito. Afinal, o quadro de referência deste seminário é de um autor que, ao escrever o seu último trabalho, denominou-o "Esboço de uma autoanálise" (Bourdieu, 2005) e fez questão de dizer que não se tratava de uma autobiografia, pois considerava esse tipo de relato "convencional e ilusório". E alguns chegaram mesmo a perguntar " $E$, se não é gênero biográfico, como o título da obra poderia indicar, então o que é?" (Passiani, 2006, p.207). Deixemos de lado esta controvérsia, secundária aos meus propósitos nesta apresentação. Vou reter-me naquilo que me parece um bom encaminhamento dado pelo próprio Bourdieu nesse livro, quando procura explicar-se e compreender-se. E, para isso, radicaliza, dizendo: "Compreender é primeiro compreender o campo com o qual e contra o qual cada um se fez" (Bourdieu, 2005, p.40).

Estas duas observações iniciais: a prática pedagógica e a noção de campo servem como uma espécie de guia neste momento. O seminário que hoje se
"Palestra de encerramento do Seminário-homenagem "Ciências Sociais na Saúde Coletiva: um habitus no campo", realizado em 9 e 10 de novembro de 2006, na Faculdade de Ciências Médicas da Unicamp. ${ }^{1}$ Departamento de Saúde Coletiva, Faculdade de Ciências Médicas, Universidade Estadual de

Campinas. Rua Tessália Vieira de Camargo, 126, Caixa Postal 6111, Distrito de Barão Geraldo. Campinas, SP, Brasil. 13.083-970

evernunes@uol.com.br 
encerra nasceu sob a égide do companheirismo e da generosidade, e, ao situar-se em redor de um professor, extrapola muito essa dimensão e coloca-se no marco teórico dos seus organizadores - o conceito de campo e a noção de habitus.

Sem dúvida, a sociologia do século XXI será devedora das contribuições feitas por Bourdieu na multiplicidade de temas que investigou, mas as suas instigantes colocações sobre o campo intelectual e científico permanecerão como balisadoras de muitas pesquisas. Portanto, assume-se a correção na formulação do quadro teórico adotado nesse seminário, que permite que se transite pela biografia, pela história e pela sociedade, como já havia ensinado, antes do sociólogo francês, o sociólogo americano Charles Wright Mills (1965, p.15). Dessa maneira, o conceito de campo favorece uma leitura além da autobiografia; Bourdieu fala em história social, que torna possível retomar a história pessoal em seus contextos, por exemplo, a que se desenvolveu nos espaços institucionais em seus desdobramentos de aulas, orientações, palestras, escritos, reuniões, planos de trabalho.

Mas, continuemos com Bourdieu.

O cuidado ao se utilizar a metodologia de Bourdieu é inerente à sua própria forma de investigar, e, como apontado por estudiosos deste autor, "apresenta uma dificuldade radical; o seu método não é suscetível de ser estudado separadamente das pesquisas onde é empregado", como analisa ThiryCherques (2006, p.28) em elaborado estudo sobre a teoria na prática. Retoma um ponto fundamental de que o seu "estruturalismo genético" ou construtivismo assenta-se na "convicção de que as idéias, não só epistemológicas, mas até mesmo as mais abstratas, como as da filosofia, as da ciência e as da criação artística são tributárias da sua condição de produção". Para Bourdieu, acreditar que existe um método, uma filosofia pura do conceito ou um trabalho científico descarnado não passa de uma "ilusão escolástica". De outro lado, uma questão presente em suas concepções é a de que somos agentes de um processo, e não atores. Em realidade, sabe-se que, em sua obra, como analisa Fernández (2003), o conceito de ator não aparece de forma explícita, sendo que o conceito de agente é frequente.

Dentro dessa linha, penso que a mais explícita contribuição que eu possa ter trazido ao campo da saúde coletiva foi buscar entendê-la em uma pluralidade temática e teórica, e, nesse sentido, as pesquisas que pude orientar visaram uma intensa relação de teoria e pesquisa de campo. Além disso, as apresentações que me precederam ofereceram uma interessante oportunidade para se pensar as ciências sociais em toda a sua complexidade, e ainda como um vasto território epistêmico, como reza a tradição do filósofo francês Michel Foucault. Retomo os temas das apresentações - primeiramente, dos meus contemporâneos que são militantes nesta área: Cecília Minayo, Madel Luz, Paulete Goldenberg, Amélia Cohn e Regina Marsiglia - como um momento de especial reflexão sobre o campo das ciências sociais. São temas que revelaram, para a área da saúde, a força teórica das ciências sociais; alicerçaram a construção de um conhecimento que deixou de ser vago e impreciso, para adquirir as marcas da cientificidade; e foram justamente essas pessoas que trouxeram maneiras peculiares e originais de leitura do social em saúde e, muitas vezes, não fizeram distinção entre abordagens sociológicas, antropológicas, históricas, políticas, num trabalho interdisciplinar cortado por diferentes tradições teóricas. As leituras de seus textos orientam nossos caminhos (o meu e o dos meus alunos) e se tornam obrigatórias em nossas pós-graduações. Se, hoje, podemos falar em um campo, esses meus contemporâneos que aqui estiveram presentes e outros que fazem parte desse grupo de agentes são, em verdade, os verdadeiros criadores de um habitus próprio de ver as ciências sociais, gerando e organizando práticas e representações, que, como gostava de dizer Bourdieu, são adquiridas e transmitidas mediante a interação social, no sentido de que o habitus é condicionante e condicionador de nossas ações. São exemplos de pesquisadoras que construíram uma verdadeira carreira acadêmica e consolidaram, com seu trabalho, a institucionalização da área. Todas têm uma história social vinculada às ciências sociais e à saúde coletiva, em um cotidiano cheio de atividades de pesquisa, ensino e serviços; lidando com objetos distintos, metodologias e arcabouços teóricos diferentes, canalizaram, para a saúde, as suas imensas capacidades intelectuais. O privilégio de compartilhar desse grupo, que trouxe tanta força e energia para um campo de encontro - a saúde coletiva -, deve ser enfatizado neste momento.

Da mesma forma, a prática pedagógica que resultou na produção de excelentes trabalhos no mestrado e doutorado, aqui apresentados, deve-se a um encontro - o do agente que acreditava ser possível formar professores e pesquisadores e de alunos que tomavam a carreira em saúde coletiva 
como um projeto; desculpem-me os ortodoxos em Bourdieu, mas eu gosto da ideia da carreira como projeto, na melhor tradição sartriana, quando diz: "o homem define-se pelo seu projeto. Este ser material supera perpetuamente a condição que lhe é dada; revela e determina sua situação, transcendendo-a para objetivar-se, pelo trabalho, pela ação ou pelo gesto" (Sartre, 1978, p.177). Somente como pequena observação, acrescento que os estudiosos do sociólogo francês apontam que

A crítica de Bourdieu a Sartre apresenta duas características gerais: de um lado, ela é inseparável da discussão do método fenomenológico, que serviu a este último como suporte epistemológico. De outro lado, ao discutir os pressupostos subjetivistas de Sartre, Bourdieu marca diferenças em relação às inúmeras críticas marxistas a este autor. (Barros Filho, 2002, p.75)

Em diversos momentos, Bourdieu (1980) escreveu sobre Sartre, e, em Esboço de autoanálise, que "Tanto para mim como para todos os que têm alguma relação com a filosofia, é claro que o personagem de Sartre exerceu, quer no âmbito intelectual, quer no domínio da política uma fascinação não destituída de ambivalência" (Bourdieu, 2002, p.44-5). Declara que a dominação de Sartre "nunca se exerceu na íntegra nesse universo", pela presença de outros intelectuais, como Guéroult e Vuillemin, Bachelard, Canguilhem, Koyré, e critica a imagem do "intelectual total", atribuída a Sartre.

Mas, voltando ao habitus, há necessidade de se acrescentar que ele se desenvolverá ao longo da vida, dentro de uma determinada matriz, que foi dada pela posição social do indivíduo, permitindo-lhe pensar, ver e agir nas mais variadas situações. O habitus traduz, dessa forma, estilos de vida, julgamentos políticos, morais, estéticos. Ele é também um meio de ação que permite criar ou desenvolver estratégias individuais ou coletivas. Adiantando a possível crítica de algo fixado (matriz), em relação ao habitus, recorro a Luc Boltanski, que, em "Usos fracos e usos intensos de habitus", observa: "Com efeito, uma sociologia centrada no conceito de habitus não pode deixar de fazer uma reflexão que se baseia em sua articulação com outras noções, sobretudo com aquela de situação" (Boltanski, 2005, p.162).

Sem dúvida, eu encontrei, na prática pedagógica, a forma de acercar-me do conhecimento, transmiti-lo e reproduzi-lo. Daí, a menção inicial à aula, que percorreu o cotidiano das minhas atividades e que traz as marcas das influências familiares, onde o magistério aparece como uma carreira possível, junto às influências de professores, muitos deles egressos da Universidade de São Paulo e da Escola de Sociologia e Política, alguns com títulos de mestrado e que despertaram o meu interesse pela sociologia. Assim, o contato com os textos de sociólogos como Fernando de Azevedo, Florestan Fernandes, Oracy Nogueira, Emílio Willems, Gilberto Freyre, e de educadores como Anísio Teixeira, Lourenço Filho na época da Escola Normal, foi decisivo na minha opção pelas ciências sociais.

A insistência na questão do ensino faz sentido, não apenas por uma orientação vocacional, mas porque ela mostrou ser a melhor forma de inserção em um ambiente que demandava ingentes esforços para dar visibilidade a um corpo de conhecimentos estranho ao ensino médico. Se, ainda hoje, a identidade das ciências sociais e humanas em saúde necessita ser continuamente refletida, numa demonstração de um corpus organizado e metodologicamente sustentado, em seus primórdios, nos anos 1960, isto era tarefa para desbravadores. Criar e formatar, para usar uma linguagem mais atual, programas de ensino centrados nos conceitos que os clássicos das ciências sociais haviam formulado e adequá-los às questões da saúde e da doença trazia novas exigências. Estas encontravam nas práticas de campo, por meio de pesquisas, uma forma de colocar estudantes em contato com uma realidade que, muitas vezes, lhes era bastante estranha. Nesse sentido, a formação marcadamente teórica, adquirida nas salas de aula da Universidade de São Paulo - com Fernando de Azevedo, Florestan Fernandes, Paul Hugon, Rui Coelho, Anita Castilho, Egon Schaden, e muitos outros - foi fundamental no momento de enfrentar o ensino em uma situação que demandava adaptações, incluindo o trabalho prático nas comunidades urbanas. Felizmente, as experiências anteriores junto a comunidades rurais (como sociólogo do Serviço Social Rural e da Superintendência de Reforma Agrária) e bairros urbanos de Campinas, e as atividades docentes na graduação na faculdade de Serviço Social nesta cidade e em duas outras cidades do interior do Estado de São Paulo (Araçatuba e São José do Rio Pardo), como professor 
no curso de ciências sociais, foram úteis nessa nova aventura - conduzir diagnósticos de saúde para instrumentalizar a discussão teórica de temas como estrutura social, classes sociais, relações de poder, extremamente complexos para estudantes de medicina cujo referencial era a biologia. O ensino, no magistério secundário, em sociologia e sociologia educacional, para o qual havia me habilitado desde 1959, em concurso público, também foi marcante quando assumi a docência em uma escola médica.

A menção à aula também nos remete novamente àqueles que fizeram de suas vidas acadêmicas uma intensa relação com estudantes e puderam dar expressão a suas brilhantes pesquisas na interação com graduandos e pós-graduandos. De um modo geral, esta foi a carreira dos cientistas sociais, em sua grande maioria.

Um ponto que se destaca neste seminário é a retomada dos conteúdos desenvolvidos, nos mestrados e doutorados, com forte conotação das ciências sociais e humanas, e que trouxeram expressiva e fundamental contribuição para o campo da saúde coletiva. Certamente, os cursos de pósgraduação possibilitaram que os cientistas sociais desenvolvessem uma extensa temática sobre a medicina e suas práticas, de um lado, e, de outro, sobre a compreensão do processo saúde-doença. Vendo em retrospecto as teses orientadas, sinto que a liberdade assegurada aos estudantes em suas propostas foi extremamente enriquecedora e possibilitou uma contínua renovação em termos teóricos e metodológicos - estudamos muito, eu e os alunos; divergimos e corrigimos rumos; concordamos muito e deixamos espaços abertos para ouvirmos as bancas de qualificação e de defesa, mas, sobretudo, procuramos compartilhar um momento extremamente tenso, que é o de narrar o que foi investigado. Este não é um problema pessoal ou dos estudantes da saúde coletiva, mas acompanha todos os professores e alunos na pós-graduação. Lembro-me de um livro intitulado A bússola do escrever: desafios e estratégias na orientação de teses e dissertações (Biancheti, Machado, 2002), coletânea que trata dessa complexa atividade de orientar; outra lembrança, neste momento, é a da conferência da antropóloga Miriam Goldenberg (2006), quando recupera autores tão caros às minhas experiências como docente, como Foucault, Elias, Becker, e que, em sua fala, situa as dificuldades na elaboração de uma tese. De Norbert Elias, a conferencista citou as dificuldades que ele teve ao escrever a tese de doutorado. Em sua autobiografia, Elias (2001, p.101-2) registra esse momento:

No que diz respeito à pesquisa, dispunha apenas de minha tese de doutorado para provar minha capacidade. E ela representara um trabalho duro. Tinha confiança em minhas capacidades intelectuais, e idéias não me faltavam. Mas o imenso trabalho intelectual que minha tese exigira me parecera dificílimo. Só bem mais tarde fui pouco a pouco compreendendo que noventa por cento dos jovens encontram dificuldades ao redigir seu primeiro trabalho de pesquisa importante; e às vezes, acontece o mesmo com o segundo, o terceiro ou o décimo, quando se consegue chegar aí. Teria agradecido se alguém me dissesse isso na época.

Elias descobre que a grande maioria tem dificuldades, iguais às encontradas por ele, mas, como escreve, foi perseverante e venceu; lembre-se que somente aos 57 anos Elias conseguiu a sua primeira posição estável como professor de sociologia.

Voltemos aos temas propriamente ditos. Certamente, o que foi visto neste Seminário não destoa do que se passou na grande maioria dos cursos de mestrado e doutorado, mesmo tomando como centralidade o campo das ciências sociais e humanas. Hoje, diferentemente da fase inicial, a diversidade foi sistematizada (ou arrumada) em linhas de pesquisas e estruturadas a partir dos grupos de pesquisas. Certamente, Bourdieu, avesso ao academicismo e à regulação institucional, discordaria desse critério. Sem dúvida, a criatividade inicial foi benéfica. Em recente trabalho, comparei a Saúde Coletiva a um mosaico, entendida como um conjunto formado por partes separadas, mas que se aproximam quando a compreensão dos problemas ou a proposta de práticas se situam além dos limites de cada "campo disciplinar", exigindo arranjos interdisciplinares. Acrescento que a sua composição está associada ou àquelas ciências de fronteira, muitas vezes já consolidadas (por ex.: psicologia social), ou às interdisciplinas (por ex.: avaliação de serviços de saúde, planejamento em saúde), ou às interciências (por ex.: ecologia). Como acrescento, "Nesse sentido, entendemos que o campo não é simplesmente 
um território opaco, um compósito de conhecimentos, saberes e práticas desarticulados, mas que se compõem de acordo com as necessidades em descrever, explicar e/ou interpretar a realidade de saúde que se deseja estudar, avaliar ou transformar; para isso, fazemos uso dos conceitos, das categorias analíticas, das chaves interpretativas procedentes do núcleo duro das ciências - o corpus teórico - que lançam suas luzes para o entendimento dos objetos e sujeitos investigados pelos pesquisadores. Agora, o mosaico transforma-se em um vitral, no qual os problemas estão filtrados pela teoria" (Nunes, 2006, p.304-5). Em verdade, a questão da teoria continua sendo o ponto central para as ciências sociais, como situa, de forma exemplar, Anthony Giddens, quando afirma que:

A teoria social tem a tarefa de fornecer concepções da natureza da atividade social humana e do agente humano que possam ser colocadas a serviço do trabalho empírico. A principal preocupação da teoria social é idêntica à das ciências sociais em geral: a elucidação de processos concretos da vida social. (Giddens, 1989, p.xiv)

Neste encadeamento, antes de situar as temáticas dos mestrados e doutorados, gostaria de considerar o espaço especial que foi aberto para as ciências sociais com a constituição da saúde coletiva como grande área de convergência de práticas teóricas, sociais, técnicas e políticas. Esse espaço, que se torna cada vez mais ampliado, tem como um dos seus pilares as ciências sociais e humanas; estas, por sua vez, renovam-se e recriam seus conceitos e categorias no enfrentamento dos problemas coletivos da saúde.

Considero acertada a ordenação dada às teses que orientei neste seminário, que, embora elaboradas em diferentes momentos, guardam relações temáticas, conceituais e metodológicas. Assim, no grupo intitulado "Saúde Mental: da contestação à construção do conhecimento", encontram-se trabalhos que versaram sobre a construção do conhecimento psiquiátrico e sobre o saber psicanalítico, assim como sobre a psicologia da saúde, incluindo um estudo que abordou a antipsiquiatria e outro que abordou as relações cidade-hospital psiquiátrico-cidade. As teses citadas no grupo "A construção social da ciência e do saber" enquadram-se em uma preocupação que foi a marca das pesquisas que realizei nos últimos anos, com a preocupação de entender o próprio campo das ciências sociais em saúde. Nelas são abordadas: as construções científicas de diversas áreas, como a odontologia, as ciências sociais em saúde, saberes sobre doenças, a interface entre campos como a etnoepidemiologia, o estudo de publicações científicas, como o caso da literatura francesa que trata da saúde na vertente sociológica e relações gênero e ciência. Em "Saúde comunitária e do trabalhador: campo de práticas sociais e políticas", há dois trabalhos sobre participação em saúde, incluindo-se em um deles detalhado estudo arqueológico do discurso sobre participação e três que tratam das relações saúde e trabalho, tanto na construção do campo da saúde do trabalhador, como de detalhada investigação sobre a trajetória de trabalhadores nos processos de transformação das relações técnicas e sociais do trabalho, e um estudo da construção de uma psicologia do trabalho no contexto do processo de industrialização no Brasil. Finalmente, em "Ensino nas ciências da saúde: medicina, enfermagem e as novas práticas", são englobados trabalhos que vão da história das primeiras escolas de medicina no Brasil, à história da enfermagem brasileira vista através das revistas que trataram da enfermagem - ensino e prática -, ao estudo da construção do conhecimento da criança pelos pediatras, à analise das transformações do ensino médico no Brasil, as questões éticas das práticas médicas e análises detalhadas das práticas alternativas e complementares.

Este é, seguindo a ideia anterior, o mosaico que se formou dos trabalhos, cujas pesquisas empíricas foram iluminadas pelas teorias as mais diversas. Há enfoques marxistas, análises do discurso, seguindo de perto a "arqueologia" de Foucault, reconstituições de campos de saberes, na tradição de Bourdieu, narrativas nas quais memória e história estabelecem diálogo, na tentativa de aproximação com Benjamin, e outros mais, como Habermas, Guatarri etc. As próximas teses não fugirão desta forma de trabalhar as ciências sociais e a saúde coletiva, o que poderia sugerir um aparente ecletismo teórico, mas que buscando um solo comum e que tem muito a ver com a perspectiva de Bourdieu, tão bem exposta por Loïc Wacquant, ao analisar a obra de seu amigo, mestre, colaborador, ao ressaltar: "seu brado por uma ciência social reflexiva, capaz de controlar seus próprios vieses, bem como se manter independente de "ritos de instituições" (Wacquant, 2002, p.95). 
Durante esta exposição, procurei narrar um pouco de uma trajetória e de um trabalho realizados em espaços institucionais e que contou com a presença de muitos amigos do Brasil e da América Latina. Nas Escolas de Saúde Pública, nos Departamentos de Medicina Preventiva, nos Institutos de Saúde Coletiva, tive a oportunidade de participar de bancas examinadoras, aulas e eventos que deram elementos importantes para as minhas atividades docentes e de pesquisa. Ressalto os latino-americanos, que, desde os anos 1970, foram partícipes em acreditar que era possível dar identidade ao campo da medicina social e em usar o instrumental das ciências sociais. Inegavelmente, a figura que dominou este cenário durante vinte e cinco anos foi Juan César García, cuja influência foi decisiva para muitos de nós. Sua perspectiva marxista iria marcar um largo período da medicina social e, mesmo após sua morte, em 1984, a sua obra continua a ser objeto de reflexão. Sobre outros que batalharam e batalham por uma sociedade mais justa e igualitária, mexicanos, colombianos, equatorianos, chilenos, argentinos, peruanos, venezuelanos, cubanos, com os quais tive a honra de trabalhar (não cito os nomes, com medo de omissões), deixo o meu testemunho de quanto foram importantes no meu percurso acadêmico. Muito aprendi sobre temas que não eram parte dos clássicos da sociologia, mas que foram fundamentais para que pudesse estruturar um pensamento mais abrangente sobre as possibilidades das ciências sociais. Todos foram agentes nessa construção.

Não é fácil elaborar esta reflexão diante de meus pares e na instituição em que estive (e, em parte, ainda estarei) durante tantos anos, onde apresentei meu doutorado e que me honrou, anos atrás, com o Prêmio que leva o nome do seu fundador - Professor Zeferino Vaz, e que acolheu, num ímpeto de inovação e crença, a mim e a outros cientistas sociais para trabalharem no campo da medicina, em uma época em que somente alguns países do primeiro mundo haviam se aventurado nesse campo. À Faculdade de Ciências Médicas e ao Departamento de Medicina Preventiva e Social (atual Departamento de Saúde Coletiva), rendo as minhas homenagens. Também, agradeço a uma Instituição que tem sido a grande possibilitadora do trabalho científico no Brasil - o CNPq -, da qual sou bolsista produtividade (IA) há algum tempo e com o grupo com o qual eu tenho trabalhado - o Comitê Assessor de Saúde Coletiva e Nutrição. O estímulo recebido e a convivência com colegas de diferentes áreas têm sido de grande importância na minha produção.

Por último, uma lembrança muito especial a duas pessoas que me acompanham ao longo desses anos. A Ecilda Maria da Silva Nunes, minha mulher, que leu todos os meus textos e de muitos dos meus alunos e, atentamente, fez as necessárias correções gramaticais, além de proveitosas sugestões; ao meu filho Rodrigo Antonio da Silva Nunes, que me ensinou o que sei de informática a fim de que eu me adaptasse minimamente às inovações tecnológicas, e que tem sido um amigo. A vocês, o meu carinho muito grande.

Renovo, ao encerrar estas palavras, um elogio e um agradecimento. Ao Nelson Filice de Barros e a Juliana Luporini do Nascimento (sociólogos, professores do Departamento de Saúde Coletiva, FCM/ Unicamp), que construíram este seminário de maneira impecável. Eu soube desta realização quando já estava tudo pronto. Trazer para a cena as Ciências Sociais pela prática desenvolvida foi um achado primoroso, especialmente no marco de referência de Bourdieu; e ter contado com a presença de muitos daqueles que exercitam essa prática foi um feito de invejável qualidade e que recupera a ideia de que todos somos agentes nesse processo de construção e consolidação de um campo. Sem dúvida, esta forma de reflexão foi exemplar, pois possibilitou, na expressão do sociólogo francês aqui inúmeras vezes citado, "desencadear um processo de auto-análise coletiva". Para ele, "estamos, hoje, em condições de conceber novas formas de reflexão. Trata-se, para tanto, de mobilizar um coletivo, em torno de interrogações relativamente elaboradas, em condições tais que se possa produzir uma verdade sobre si próprio que, certamente, ele é o único capaz de produzir" (Bourdieu, 2004, p.17-8). 


\section{Referências}

BARROS FILHO, C. O habitus e o nada. Rev. FAMECOS, n.17, p.74-88, 2002.

BIANCHETI, L.; MACHADO, A.M. (Orgs.). A bússola do escrever: desafios e estratégias na orientação de teses e dissertações. Florianópolis: Ed. da UFSC, 2002.

BOLTANSKI, L. Usos fracos e usos intensos do habitus. In: ENVREVÉ, P.; LAGRAVE, R-M. (Orgs.). Trabalhar com Bourdieu. Trad. Karina Jannini. Rio de Janeiro: Bertrand Brasil, 2005. p.155-63.

BOURDIEU, P. Esboço de uma auto-análise. Trad. Sérgio Miceli. São Paulo: Companhia das Letras, 2005

Os usos sociais da ciência: por uma sociologia clínica do campo científico. Trad. Denice Bárbara Catani. São Paulo: Editora Unesp, 2004.

Sartre. London Rev. Books, v.2, n.22, p.11-2, 1980

ELIAS, N. Norbert Elias por ele mesmo. Trad. André Telles. Rio de Janeiro: Jorge Zahar, 2001

FERNÁNDEZ, O. Pierre Bourdieu: ¿Agente o actor? Tópicos del Humanismo, n.90, 2003. Disponível em: <http://cariari. ucr.ac.cr/\% 7Eoscarf/textos/3Ab3b2A.html>. Acesso em: 5 out. 2006

GIDDENS, A. A constituição da sociedade. Trad. Álvaro Cabral. São Paulo: Martins Fontes, 1989.

GOLDENBERG, M. Conferência de Abertura da VII Jornada dos Alunos do PPGSA. Enfoques, v.5, n.1, p.95-103, 2006.

PASSIANI, E. Imposturas intelectuais: a sociologia (auto)crítica de Pierre Bourdieu. Novos estud. - CEBRAP, n.74, p.207-12, 2006.

ROSA, J.G. Grande sertão: veredas. Rio de Janeiro: Nova Fronteira, 1984

THIRY-CHERQUES, H.R. Pierre Bourdieu: a teoria na prática Hermano. Rev. Adm. Publica, v.40, n.1, p.27-55, 2006.

WACQUANT, L.J.D. O legado sociológico de Pierre Bourdieu: duas dimensões e uma nota pessoal. Rev. Sociol. Polit., n.19, p.95-110, 2002.

WRIGHT MILLS, C. A imaginação sociológica. Trad. Waltensir Dutra. Rio de Janeiro: Zahar, 1965. 
UM AGENTE NA CONSTRUÇÃO DO HABITUS ...

\begin{abstract}
A apresentação reproduz o depoimento feito pelo autor quando do Seminário realizado em sua homenagem, em 2006, por ocasião da sua aposentadoria. Nela o autor relembra alguns fatos da sua carreira como cientista social da saúde, situando-a no quadro de referência do seminário - a noção de campo e habitus. Situa a sua contribuição para o campo das ciências sociais e da saúde coletiva, especialmente relacionada às dissertações e teses que orientou.

Palavras-chave: Campo. Habitus. Ciências Sociais. Saúde Pública. Depoimento.
\end{abstract}

An agent in the construction of social sciences habitus in collective health

This presentation reproduces the personal testimony made by the author in the Seminar held in his honor in 2006 on the occasion of his retirement. In it the author recalls some facts of his career as a health social scientist, placing it in the framework of the seminar - the notion of field and habitus. The author highlights their contributions to the field of social sciences and public health, especially related to dissertations and theses that he directed.

Keywords: Field. Habitus. Social Sciences. Public Health. Statement.

Un agente en la construcción del habitus de las ciencias sociales en salud colectiva

La presentación reproduce el testimonio hecho por el autor en el Seminario celebrado en su honor en 2006, con motivo de su jubilación. En ella, el autor recuerda algunos hechos de su carrera como científico social de la salud, situándolo en el marco del seminario - las nociones del campo y habitus. El autor analiza su contribución en el campo de las ciencias sociales y de la salud colectiva, especialmente en relación con disertaciones y tesis dirigidas.

Palabras clave: Campo. Habitus. Ciencias Sociales. Salud Pública. Testimonio.

Recebido em 24/05/12. Aprovado em 18/08/12 